\title{
Mida lemmikud vajavad? Teadus loomade heaolust
}

Raivo Mänd

\begin{abstract}
Teesid
Ühiskonna mure inimeste peetavate lemmik-, kodu-, katse- ja loomaaialoomade heaolu pärast on viimasel paaril aastakümnel järsult kasvanud. Peamisteks probleemideks, mis inimeste peetavate loomade heaolu tugevasti kahjustavad, on paljudele loomapidajatele omased antropotsentrism ja antropomorfism. Kuigi vaidlused selle üle, millist elukvaliteeti inimene-loomapidaja on oma lemmikule konkreetselt kohustatud tagama, alles kestavad, on enamvähem lepitud kokku selles, et loomale tuleb võimaldada talle loomupäraselt omast elustiili, vältida kestvate ja tugevate negatiivsete emotsioonide (hirmu, valu jt) osakssaamist, pakkudes samal ajal loomulikke naudinguid ning tagades tema rahuldav tervis ja kasv ning füsioloogiliste ja käitumuslike süsteemide normaalne funktsioneerimine.
\end{abstract}

Märksõnad: antropomorfism, antropotsentrism, eelistuskatse, lemmikloomad, loomakaitse, loomapidamise eetika, loomapsühholoogia, operantkatse

Ühiskonna mure inimeste peetavate lemmik-, kodu-, katse- ja loomaaialoomade heaolu pärast on viimasel paaril aastakümnel järsult kasvanud. 1980. aastal avaldas Oxfordi Ülikooli loomakäitumise professor Marian Stamp Dawkins raamatu Animal Suffering: The Science of Animal Welfare (London: Chapman and Hall), mis võttis kokku seni selles vallas tehtud uurimuste põhitulemused ja püstitas loomade heaolu uurijate ette eesmärgid järgmiseks perioodiks. Sestpeale kasvas seda ala käsitlevate teadustööde arv oluliselt ja juba 1992. aastal asutati ka vastav rahvusvaheline teadusajakiri Animal Welfare (Loomade heaolu).

Peamisteks probleemideks, mis inimeste peetavate loomade heaolu tugevasti kahjustavad, on paljudele loomapidajatele omased antropotsentrism ja antropomorfism.

Antropotsentrismi olemus antud kontekstis seisneb selles, et tihti suhtutakse loomade pidamisse utilitaarselt, üksnes inimese huvide seisukohast. See, kas loom pidamistingimuste all kannatab

http://haldjas.folklore.ee/tagused/nr31/raivomand.pdf 


\section{Raivo Mänd}

või mitte, pakub sellisele loomapidajale huvi vaid sedavõrd, kuivõrd see märgatavalt kahjustab tema enda utilitaarseid huve (kui näiteks tuleb maksta haige looma ravimise eest või väheneb lehmade piimaand või kui naabrid kaebavad).

Antropomorfism on salakavalam häda. Loomapidaja ise võib küll soovida oma lemmiku elu nii meeldivaks muuta kui iganes võimalik, kuid samas puudub tal arusaam, et erinevat liiki loomad vajavad heaoluks sootuks muud kui inimene ise. Loomad ei ole karvased ja sulised inimesed. Vaevalt näiteks tunneb koer kuigi palju rõõmu värvikirevaks maalitud ja aknakestega kuudist, küll aga ehk sületäiest põhust kuudi põrandal. Laps ei pruugi aga teada, et kanaarilinnule on puuri magamiseks vaja õrt, mitte tillukest voodikest.

Kuigi vaidlused selle üle, millist elukvaliteeti inimene-loomapidaja on oma lemmikule konkreetselt kohustatud tagama, alles kestavad (see ei olegi teaduslik, vaid eetilis-moraalne küsimus, millel ei pruugi olla väga ühest vastust), on viimasel ajal enam-vähem lepitud kokku järgmistes põhipunktides:

1) loomale tuleb pakkuda talle loomupäraselt omast elustiili, mis teeb tal võimalikuks oma loomulike kohastumuste ja võimete kasutamise. Kui ikka lind tunneb end magamise ajal kõige kindlamalt oksal istudes (milleks looduslik evolutsioon on tema jala ehituse kohandanud), tuleb talle seda võimalust ka puuris pidamisel pakkuda. Vastav õrs on selleks omal kohal;

2) tuleb vältida kestvate ja tugevate negatiivsete emotsioonide (hirmu, valu jt) osakssaamist loomale, samas tuleb talle pakkuda loomulikke naudinguid. Hiirtel on sünnipärane hirm kassi lõhna vastu, ärme siis sunnime teda elama kogu elu kassiga ühes ruumis. Samas on oravad harjunud kiiresti jooksma ja oksalt oksale hüppama - nn oravaratas puuris võimaldab tal ehk oma aktiivsusvajadust kas või osaliseltki rahuldada;

3) ja lõpuks, loomale tuleb tagada rahuldav tervis, kasv ja füsioloogiliste ning käitumuslike süsteemide normaalne funktsioneerimine.

Kuidas seda aga teada saada, kas ja kuivõrd on ülaltoodud tingimused täidetud? Siinkohal tulebki appi tulla teadusel. Loomade seisundi ja heaolu hindamiseks on kasutusel rida kaudseid meetodeid, millest igaühel on oma eelised ja puudused. Vaatleme neid alljärgnevalt. 
Füüsilise tervise hindamine. Niisamuti nagu ema võib kraadida oma beebit, kes pole veel suuteline ise oma hädasid kurtma, või viia ta arsti juurde ja lasta analüüsida tema vere- või uriiniproovi, võib ka loomal mõõta mitmesuguseid füüsikalisi, meetrilisi ja füsioloogilisi parameetreid, mis seonduvad tema tervisliku seisundiga. Akuutsemate haigusjuhtude puhul võib sellest kohe kasu olla, kuid krooniliste hädade väljaselgitamisel võib tulla ette raskusi. Tihti on näiteks mitmesuguste verenäitajate väärtuste tõlgendamine keeruline isegi palju-uuritud inimese puhul, saati siis veel loomade puhul, kelle vastavate parameetrite liigisisesest muutlikkusest ja selle põhjustest on vähe teada. Näiteks võib laialt kasutatava verenäitaja - hematokriti - väärtus olla madal nakkushaiguse tagajärjel, kuid ka alatoitluse tõttu. Võta siis kinni, mida tuleks lemmiku päästmiseks õieti teha - kas muuta tema toiduratsiooni või ravida mingit haigust. Lisaks sellele, et niisuguste "tervisenäitajate" tõlgendamine on tihti vastuoluline, rõhutavad loomade heaolu uurijad veel teistki puudust - nimelt ei peegeldavat sellised näitajad oletatavaid vaimseid kannatusi.

Füsioloogiliste vastuste (näiteks stressi) mõõtmine. Püsivamate, sealhulgas ka vaimsete kannatuste olemasolu väljaselgitamiseks nii loomadel kui ka inimesel on kasutusel spetsiaalsed füsioloogilised testid, mis reedavad näiteks kroonilise stressi olemasolu. Kuid ka selliste näitajate tõlgendamine on tihti vastuoluline - näiteks pole päris selge stressinäitajate seos looma tegelike kogemustega. On andmeid, et püsiva stressi sündroomi võivad mõnikord esile kutsuda hoopis vägagi positiivsed elamused.

Vabalt elavate liigikaaslastega võrdlemine. Paljudel koduja lemmikloomadel on looduses vabalt elavaid liigikaaslasi, kelle eluviiside põhjalik jälgimine võimaldab meil saada aimu, millised on need elulised vajadused ja harjumused, mida tuleks kodus peetavaile loomadele pakkuda. Teades, et hülged elavad vees, ehitab loomaaednik nende puuri kindlasti basseini. Kuid elu looduses on siiski väga erinev sellest, mis on võimalik vangistuses. Tihti pole looduses esinevaid hüvesid võimalik loomale pakkuda lihtsalt puhtmajanduslikel kaalutlustel, ja targem on mõelda asenduslahenduste peale. Siin sobib näitena jällegi ülalkirjeldatud oravajuhtum: kui oraval on enda vormishoidmiseks vaja füüsilist aktiivsust, siis selle asemel, et ehitada talle nii suur puur, kuhu mahuks puu, mille otsas turnida, piisab ehk lihtsalt oravaratta paigutamisest puuri. 


\section{Raivo Mänd}

Teiseks: elu looduses on tihti karm ega pruugi loomale sugugi vähe kannatusi tuua. Metsik loodus on täis haigusi, kiskjaid ja muid ohte. Äkki kompenseerib nendest vabastamine nii mõnegi puuduse, mis puurielus ette tuleb?

Kolmandaks on võrdlus vabalt elavate liigikaaslastega riskantne juba selletõttu, et pikaajalise aretus- ja kodustustöö tulemusena on koduloomad tihti niivõrd hästi kohastunud just "kunstlike" elutingimustega, nii et looduslikematesse oludesse viimine ei pruugi neile mingit õnne tuua.

Looma käitumise jälgimine. Sageli teeb inimene järeldusi sellest, kuidas loomad end parajasti tunnevad, nende käitumise järgi. "Ebanormaalne" käitumine arvatakse enamasti olevat seotud kannatustega. Selline järeldus on kerge tulema, jälgides puuris peetavat rebast, kes tundide kaupa pendeldab ühest puuri seinast teise ja tagasi nagu kurjast vaimust vaevatu. Looduses ei tee ta nii ju kunagi, järelikult on tal kohutav stress! Ta tuleks sellest vabastada, siis ta enam nii ei käituks! Kuid pole võimatu, et rebane on leidnud endale sellises liikumises "aseaine", millega ta kompenseerib pealesunnitud ruumikitsikust ja vähest aktiivsusevõimalust. Pole võimatu, et rebane niimoodi käitudes ei kannata, vaid hoopis mõnuleb!

Need kõik olid kaudsed meetodid, mille abil inimene võib hinnata seda, kuidas loomad end tema käe all tunnevad. Niisamuti püüab lapsevanem kaudsete võtete abil välja selgitada oma tita tervislikku ja emotsionaalset seisundit. Loomade puhul näivad kaudsed meetodid esmapilgul olevat lausa asendamatud, sest loomad teatavasti ju ei räägi. Kuid kas asi on ikka nii lootusetu?

Oma 2003. aastal ilmunud artiklis "Behaviour as a tool in the assessment of animal welfare" kirjeldab Marian S. Dawkins eksperimentaalseid teaduslikke meetodeid, mida etoloogid on kasutanud loomade vajaduste väljaselgitamiseks (Dawkins 2003). Need on meetodid, mis sõna otseses mõttes võimaldavad küsida loomalt endalt, mida ta õieti vajab. Kõige vanemad ja tänaseni laialt kasutusel olevad meetodid on eelistuskatsed ja operantkatsed.

- Eelistuskatsetes antakse loomale valida näiteks erinevate toiduobjektide, mänguasjade, puuritüüpide jne vahel, et näha, millist ta eelistab. Katsetes kasutatakse selleks sageli T-kujulist labürinti, mille lahknemiskohas peab loom valima, kummas labürindi harus paikneva objekti juurde ta läheb. Eelistuskatseis võib loomale pak- 
kuda kaht või mitut objekti. Katset korratakse palju kordi. Kui soovitakse teada saada loomaliigi või -tõu, mitte indiviidi eelistust, tehakse katseid mitme erineva loomaga;

- Operantkatse on sisuliselt eelistuskatse erivorm, ainult selle vahega, et seekord loomale ei näidata neid objekte, mille vahel ta valima peab, vaid lastakse tal vajutada ühele või teisele klahvile, mispeale ta saab selle või teise objekti. Eelnevalt õpetatakse talle muidugi selgeks, mida emma-kumma klahvi vajutusest võib loota. Katsed viiakse tavaliselt läbi erilises ruumis, mida kutsutakse standardseks operantkambriks või Skinneri boksiks.

Kuigi esmapilgul võivad eelistus- ja operantkatsed tunduda väga head ja usaldusväärsed, on ka neil tegelikult siiski rida puudusi.

Kõigepealt, need katsed võimaldavad hinnata üksnes suhtelist eelistust, mitte aga absoluutset vajadust. Kui kassipojale anda valida lõngakera ja kummipalli vahel, võib ta valida kummipalli, kuid see ei ütle veel, kui suur on üldse tema mängimisvajadus ja kui tugevasti ta kannatab selle võimaluse puudumise all.

Teiseks, eelistuskatsetes on alati oht, et mingi hetke-eelistus domineerib pikaajalise vajaduse üle. Kui isasele loomale näidata indlevat vastassugupoolt, võib temas lõkkele puhkeda vastupandamatu kopuleerumissoov, kuigi ta samal ajal on vitamiinivaegusest nõrkemas ja pikas perspektiivis oleks hoopis kasulikum valida seda vitamiini sisaldav toit.

Kolmandaks, vangistuses peetava looma elutingimused on sedavõrd kunstlikud ja katsetaja poolt valimiseks pakutavad objektid võivad sedavõrd erineda looduses esinevaist, et looma enda eelistused ei anna objektiivset aimu tema tegelikest vajadustest. Siinkohal võib tuua näite kas või inimesest enesest, kes ju ka elab tänapäeval maailmas, mis on tohutult erinev sellest, millises elasid meie esivanemad nende aastatuhandete jooksul, mil looduslik valik vormis inimliigi loomulikud eelistused. Tollal näiteks olid suhkruid sisaldavad toidud haruldased ja magusa eelistamine ei kujutanud meie esivanemate tervisele mingit ohtu, vaid vastupidi, oli väga kasulik. Tänapäeval, kus tööstuslikult toodetav suhkur on äkki muutunud üliodavaks ja laialt levinud toiduaineks, põhjustab magusa eelistamine inimestel hammaste lagunemist, suhkruhaigust, südameinfarkte jms.

Neljandaks - loomad, niisamuti nagu inimesedki, on väga uudishimulikud ja tunnevad tihti kõrgendatud huvi mõne objekti vastu 


\section{Raivo Mänd}

lihtsalt sellepärast, et see on nende jaoks uudne, mitte aga sellepärast, et nad seda hädasti vajavad.

Valikud, mida loomad teevad eelistuskatsetes, ei ole sageli üksteist välistavad. Kui koer, keda sunnitakse valima kondi ja lihatüki vahel, valib kondi, ei tähenda see, et ta lisaks kondile liha ei vaja.

Mida siis ikkagi teha? Kas on kuidagi siiski võimalik suhteliste eelistuste asemel hinnata ka looma absoluutseid vajadusi? Selle ülesande täitmiseks on väga perspektiivseks osutunud majandusteadusest, täpsemalt mikroökonoomikast laenatud idee - tarbijate nõudluse elastsuse hindamine. Majandusteaduses on selleks kasutusel mitmeid erinevaid indekseid, mis kõik mõõdavad pisut erinevaid asju.

Loomade vajaduste väljaselgitamiseks on osutunud sobivaimaks hinnaelastsuse indeksi arvutamine. See indeks nimelt mõõdab, kuivõrd muutub mingi kauba tarbimismäär pärast seda, kui tõuseb kauba hind. Kui kauba tarbimise suhteline muutus ületab hinna suhtelise muutuse, on nõudlus hinnaelastne ehk siis reaalne hädavajadus selle kauba järele pole kuigi suur. Vastupidi, kui kauba tarbimise suhteline muutus on väiksem hinna suhtelisest muutusest, on nõudlus jäik, mis tähendab, et objektiivne vajadus selle kauba järele on suur. Ühesõnaga, mida jäigem on nõudlus, seda hädavajalikum on vastav kaup tarbijale.

Keegi vist ei kahtle, et näiteks soola tarbimine jääks hinna tõustes ikka enam-vähem endisele tasemele, samas kui trühvlikompvekite hinna tõustes sama protsendi võrra väheneks nende tarbimine oluliselt.

Kuidas mõõta hinnaelastsust loomadel? Esimene selline katse tehti juba enam kui kümme aastat tagasi koduseaga (Matthews \& Ladewig 1994). Nimetatud teadlased panid sea ülalmainitud standardsesse operantkambrisse ja õpetasid teda vajutama erinevaid klahve, et saada erinevaid hüvesid. Ühe klahvi vajutus näiteks andis süüa, teise klahvi vajutus avas ukse naaberruumi, kus oli teine siga, kolmanda klahvi vajutus avas ukse lihtsalt tühja naaberruumi.

Seejärel hakkasid nad muutma hüve saamiseks vajalike klahvivajutuste arvu. Kui näiteks toidu saamiseks oli ühel juhul vaja klahvile vajutada viis korda ja teisel juhul kümme korda, oli toit teisel juhul järelikult kaks korda "kallim". Sel moel oli võimalik mõõta, kuidas muutus sea motivatsioon üht või teist hüve omada vastavalt sellele, kuidas muutus selle hüve hind. 
Selgus, et näljane siga soostus klahvi vajutama ükskõik kui palju, peaasi et süüa saaks. Järelikult on näljase sea toiduvajadus suhteliselt jäik ja toit seega hädavajalik. Märksa hinnaelastsem oli sea sotsiaalse kontakti vajadus - kui ukse avamiseks teise sea juurde oli vaja vajutada klahvi palju kordi, kahanes sea huvi selle toimingu vastu üsna kiiresti. Kõige hinnaelastsem ja järelikult kõigist kolmest tühiseim oli aga sea vajadus uurida ukse taga asuvat tühja ruumi - juba kümmet klahvivajutust põlgas siga liiga kalliks, et üldse selle ruumi vastu huvi tunda.

Alates sellest pioneerlikust tööst on teised loomade käitumist uurivad teadlased mitmesuguste vajaduste hinnaelastsuse mõõtmist praktiseerinud paljudel muudelgi loomadel ja tänapäeval peetakse seda loomade heaolu uuringutes kõige eesrindlikumaks ja efektiivsemaks meetodiks. Selle meetodi vaieldamatuks vooruseks, nagu eespool öeldud, on see, et niiviisi saab hinnata mitte üksnes suhtelisi eelistusi, vaid loomade tõelisi vajadusi ühtede või teiste elutingimuste, toidutüübi jms järele.

Kasutades kõiki ülalnimetatud kaudseid ja eksperimentaalseid uurimismeetodeid ning neid pidevalt täiustades, koguneb teadlastel tasapisi aina uut objektiivset informatsiooni, mis võimaldab loomapidajail oma lemmikloomade vajadusi ja heaolu järjest paremini tunda ning vastavalt ka parandada.

\section{Kirjandus}

Dawkins, Marian Stamp 1980. Animal Suffering: The Science of Animal Welfare. London: Chapman and Hall.

Dawkins, Marian Stamp 2003. Behaviour as a tool in the assessment of animal welfare. Zoology 106, lk 383-387.

Matthews, Lindsay R. \& Ladewig, Jan 1994. Environmental requirements of pigs measured by behavioural demand functions. Animal Behaviour 47, lk 713-719. 